Eval uat i on of a new y desi gned endoscope for observing i nner wall of I arge arteries for the use of endovascul ar i nt ervent i on

\begin{tabular}{|l|l|}
\hline 著者 & $\begin{array}{l}\text { Tanaka Shi nobu, Suzuki T. , Ogawa M t suhi ro, } \\
\text { Not oi Kosuke, Nogawa Masami chi, Ont ake } \\
\text { H roshi, hat anabe Go, Yanakoshi Keni chi }\end{array}$ \\
\hline $\begin{array}{l}\text { j our nal or } \\
\text { publ i cat i on ti tl e }\end{array}$ & $\begin{array}{l}\text { Pr oceedi ngs of the Annual I nt er nat i onal } \\
\text { Conf er ence of the I EEE Engi neer i ng in Medi ci ne } \\
\text { and Bi ol ogy Soci et y, EMBS }\end{array}$ \\
\hline nunber & 6090114 \\
\hline page r ange & $345-348$ \\
\hline year & $2011-01-01$ \\
\hline URL & ht t p: //hdl . handl e. net /2297/30181 \\
\hline
\end{tabular}




\title{
Evaluation of a Newly Designed Endoscope for Observing Inner Wall of Large Arteries for the Use of Endovascular Intervention
}

\author{
S. Tanaka, Member, IEEE, T. Suzuki, M. Ogawa, Member, IEEE, K. Motoi, Member, IEEE, \\ M. Nogawa, Member, IEEE, H. Ohtake, G. Watanabe and K. Yamakoshi, Member, IEEE
}

\begin{abstract}
A prototype endoscope for observing inner wall of large arteries was specially designed and evaluated through in vitro and in vivo tests. The purpose of this endoscope is to visualize the inner wall of large arteries, e.g., an aorta, without blocking off the blood stream aiming for the use of an assistive technique for endovascular interventions such as stent-graft placement for aortic aneurysm. The technique newly introduced for this purpose was the use of intermittent high-pressure saline jet synchronized to heart beat (diastolic phase). In the previous studies using commercially available bronchoscopes, we confirmed the validity of the system utilizing this technique $[1,2]$. In this study, we have specially designed a new endoscope for this purpose and evaluated. From in vitro tests using a mock circulation system, it was confirmed that the newly designed endoscope was capable of visualizing a target installed on an inner surface of the mock system. Also confirmed through in vivo tests using swine was that we could observe bifurcation in descending aorta, e.g., left renal artery, without stopping off the blood stream.
\end{abstract}

\section{INTRODUCTION}

$F^{\circ}$ OR minimally invasive endovascular therapy, vascular endoscopes with balloon have been commercially available [3] and widely used for visually inspecting inner wall of blood vessels. However, application of this method is limited to only small arteries because it requires blockage of blood flow by the balloon $[4,5]$. On the other hand, there have been strong requirement for visually inspecting inner wall of large arteries such as aorta in case of stent-graft treatments for aortic aneurysms and so on [6]. Based on this requirement, we have been developing a prototype endoscope system applicable for large arteries without blocking off the blood flow, and preliminary results of in vitro and in vivo tests were reported [1, 2]. In this study, a new endoscope was specially designed for this purpose and some results of performance tests in vitro and in vivo are presented.

Manuscript received April 15, 2011. This work was partly supported by the Second Stage of the Knowledge Cluster Initiative Project (Hokuriku Innovation Cluster for Health Science), Ministry of Education, Culture, Sports, Science and Technology.

S. Tanaka, T. Suzuki, M. Ogawa, K. Motoi, M. Nogawa and K. Yamakoshi are with the Graduate School of Natural Science and Technology, Kanazawa University, Kanazawa, 920-1192 Japan (Phone; +81-76234-4736 \& Fax: +81-76-234-4738; e-mail: shinobu@ t.kanazawa-u.ac.jp).

H. Ohtake and G. Watanabe are with the Graduate School of Medical Science, Kanazawa University, Kanazawa, 920-8641 Japan.

\section{System DESCRIPTION}

Fig. 1 shows a basic concept for visualizing inner wall of large arteries without stopping blood flow. Intermittent saline jet is discharged from the tip of an endoscope. Timing of the jet discharge is synchronized to diastolic phase (minimal blood flow phase) so as to obtain more clear view of the wall. Synchronized to discharge, endoscopic view (movie) is captured and displayed on a monitor. During the other phase (systolic phase without saline jet flow), the latest picture of the captured view (still picture) is displayed so as to obtain "pseudo-movie" of the wall during whole cardiac beat.

In Fig. 2, photographs of the newly designed endoscope for this purpose are shown. It is a two channel fiber scope with outer diameter of $6.2 \mathrm{~mm}$. Other main specifications are as follow;

$>$ Channel diameter: saline: $1.8 \mathrm{~mm}$, forceps: $2.0 \mathrm{~mm}$

$>$ Effective length: $550 \mathrm{~mm}$

$>$ Flexion angle: up: 90deg, down: 90deg

The forceps channel was installed for the future use of endovascular intervention. At the top of the tip (see Fig. 3), a special hood called "Hemo-visor" was installed for improving the ability of blood stream blockage [2].

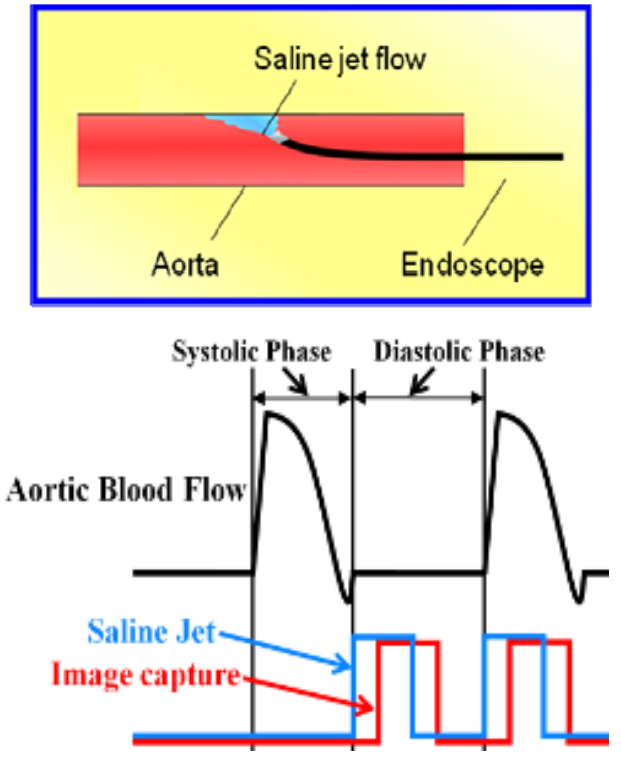

Fig. 1 Basic concept for observing inner wall of large arteries using intermittent saline jet flow 
Fig. 4 shows an outline of the saline-jet discharge control system. A saline tank (capacity: 5 litters, max. pressure: 0.6 $\mathrm{MPa}$ ) was pressurized by a conventional air cylinder. At the outlet port of the tank, a high-speed solenoid valve (A2013, Precision Dynamics Co. Ltd.) was connected to control timing and amount of the jet stream. For in vitro tests, the valve was operated by pulse signal generated by a function generator or operating signal of a pulsatile pump (see Fig.5) via a solid state relay. For in vivo tests, on the other hand, the pulse signal was triggered by ECG R-wave.

\section{MATERIALS AND METHODS}

Fig. 5 shows an experimental set up of in vitro test for evaluating visualization performance of the prototype system. A part surrounded by a red solid square shows a mock circulation system which composed of (i) a compressed air driven pulsatile pump, (ii) an air chamber mimicking aortic compliance, (iii) a valve mimicking total peripheral resistance, (iv) a reservoir mimicking atrium, and (v) an acrylic tube for the endoscope insertion on the inner surface of which an observation target is installed (see the right lower part of Fig. 5). The fluid used was bath salts solution (10g/l; mainly sodium bicarbonate) color of which was milky white (impossible to observe the target through this solution). The driving condition of the pulsatile pump and circulation parameters were adjusted as follows considering the physiological values of male adults at rest;

$\checkmark$ pumping rate : $60 \mathrm{bpm}$

$\checkmark$ duty ratio: $30 \%$

$\checkmark$ mean pump flow: $6 \mathrm{l} / \mathrm{min}$

$\checkmark$ mean pressure: $100 \mathrm{mmHg}$

$\checkmark$ pulse pressure: $50 \mathrm{mmHg}$

(systolic: $130 \mathrm{mmHg}$, diastolic: $80 \mathrm{mmHg}$ )
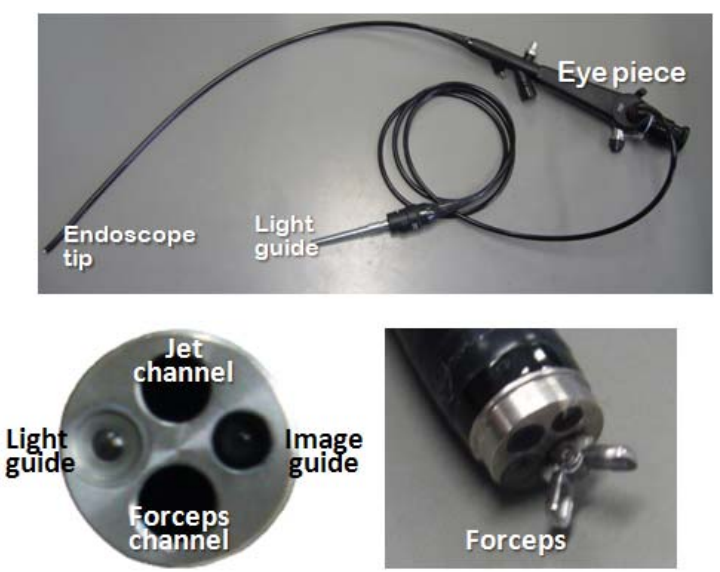

Fig. 2 Photographs of the newly designed endoscope

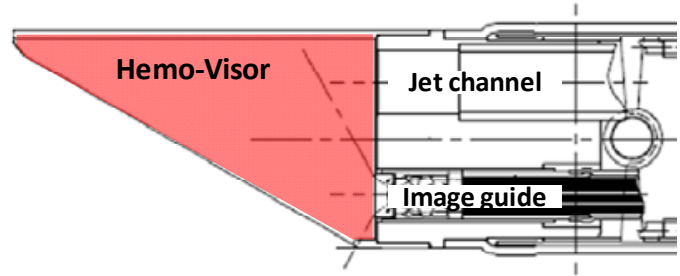

Fig. 3 Detail of the endoscope tip

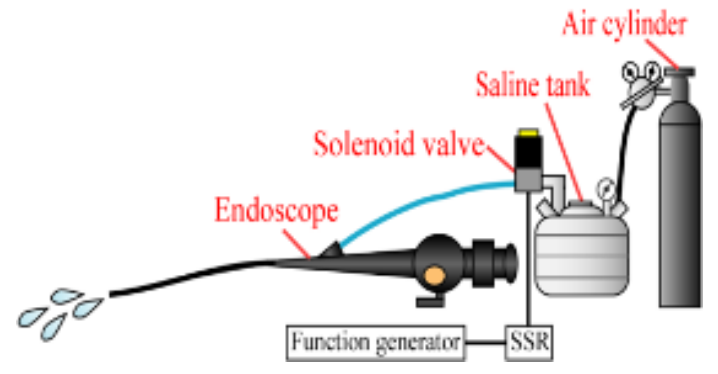

Fig. 4 Outline of the saline discharge system
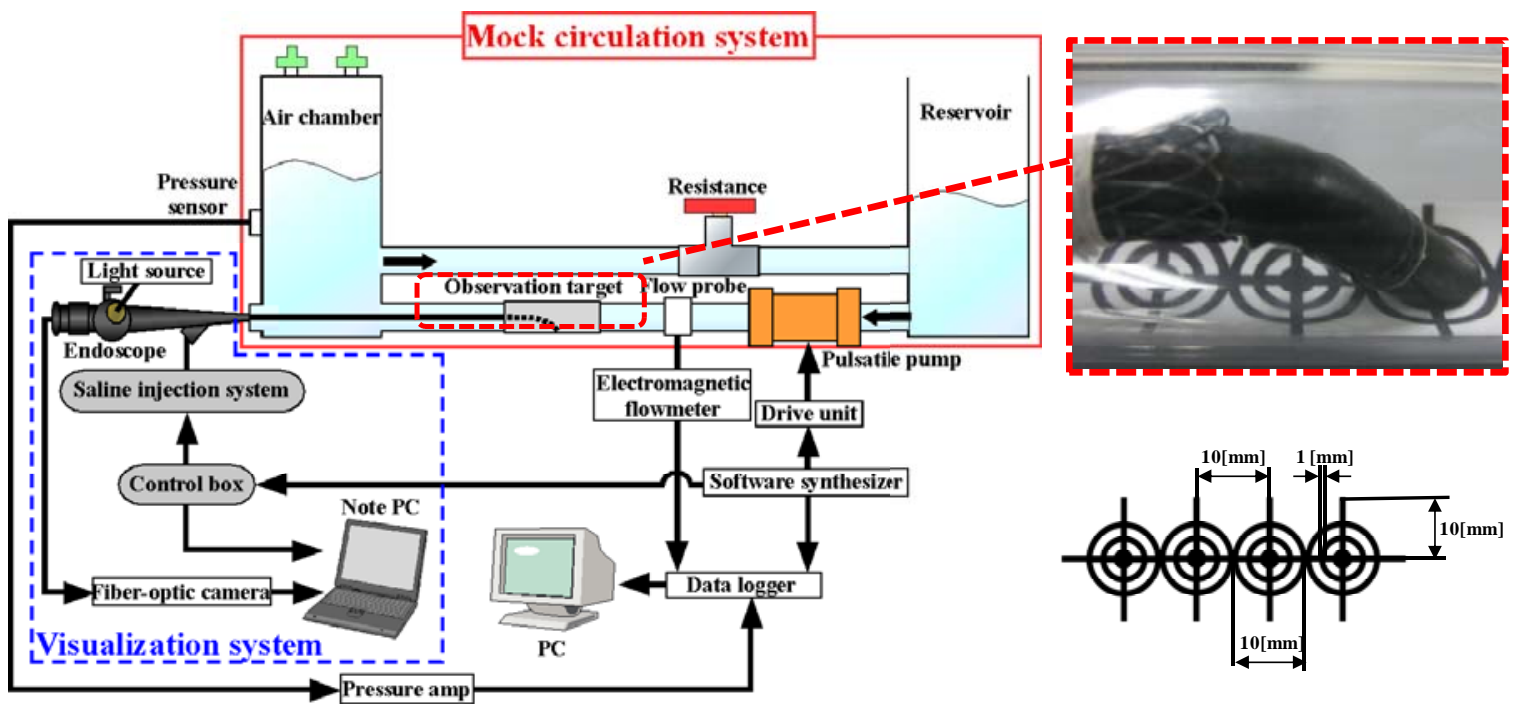

Fig. 5 Outline of the experimental set up for in vitro test 
The tip of the endoscope was inserted retrogradely into the tube and fixed using a specially made lantern-shaped stent (see the right upper part of Fig. 5). The intermittent saline jet flow made by the injection system was discharged from the saline channel during the diastolic phase of the pulsatile pump. For synchronization, the driving signal of the pump was used.

For quantitative evaluation of the "clearness" of the obtained picture (movie) of the target, we used an index of "visualization scale" which was a difference of the value of brightness between the black line and the white part of the target [2]. Before the experiments, the mock system was once filled with water and the picture of the target obtained by the endoscope was recorded and the value of brightness of the each two part were calibrated to " 0 " for the black line and " 255 " for the white part, respectively. And thus, the value of the visualization scale of the most "clear" picture will be " 255 ", and the worst will be " 0 ", which means "all white". According to the opinion of an expert in endoscope operation (a cardio-vascular surgeon), the value of the scale lower than "30" was judged as "unclear" level.

During the experiments, a parameter: $\mathrm{Td}$, which was the delay time of the solenoid valve operation (opening) from the trigger signal (pump driving signal), was changed from 50 to $550 \mathrm{msec}$ and the quality of the picture was quantitatively assessed by the scale. Also changed was the tip configuration, i.e., with or without "Hemo-visor". As mentioned before, the "Hemo-visor" is our original naming of a small hood attached on the top of the endoscope tip expecting an effective role in keeping the saline solution between the endoscope tip and the target against the fluid (blood) stream to more clearly obtain the picture.

Fig. 6 shows an outline of the in vivo tests. Altogether 5 swine weighing about $30 \mathrm{~kg}$ were used. They were anesthetized with halothane + nitrous oxide and ventilated by a respirator with room air and oxygen. The endoscope was introduced from the abdominal aorta and inserted proximally about $30 \mathrm{~cm}$. At this point, saline discharge was started using ECG-R wave as a triggering signal. In case of difficulty in obtaining stable ECG, pulse signal generated by the PC was used. To confirm the location of the endoscope tip, angio graphs were simultaneously taken (ARCADIS Avantic, Siemens AG).

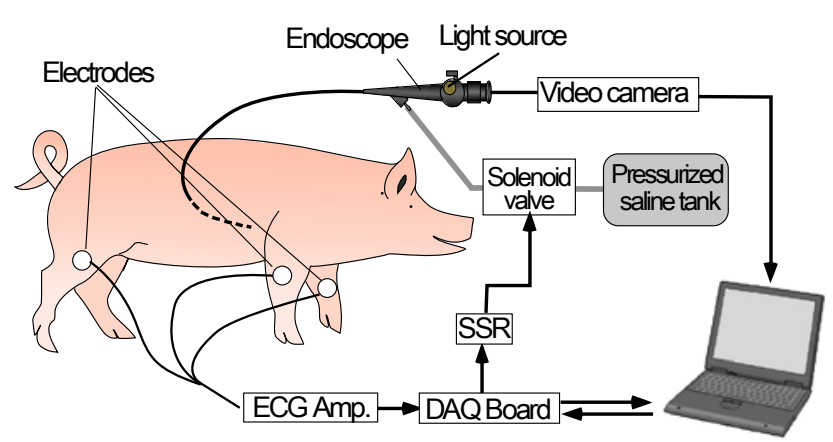

Fig. 6 Experimental set up for in vivo experiment

\section{RESULTS AND DISCUSSION}

Fig.7 is the results of in vitro tests showing the values of visualization scale versus time under the various delay time (Td) without (upper) and with (lower) Hemo-visor (H-V). Regarding the results of "without $\mathrm{H}-\mathrm{V}$ ", almost all of the plots were within the "Unclear" region (under 30), especially with the short delay time. The plots over " 30 " were observed only when the timing of the discharge was synchronized to diastolic phase (Td: 350-550msec), but the scale values were less than 50 .
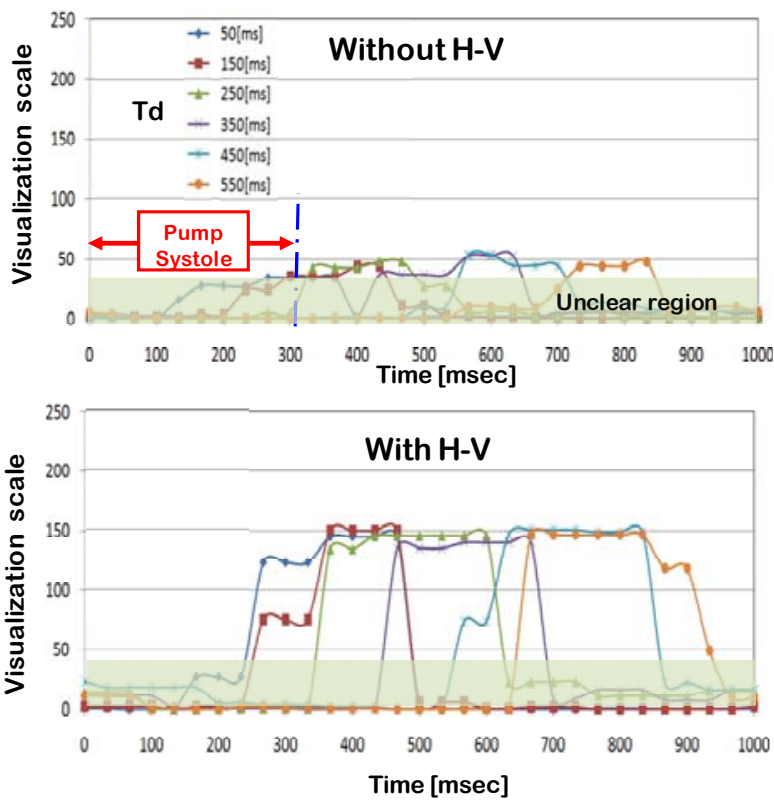

Fig. 7 Results of in vitro performance test
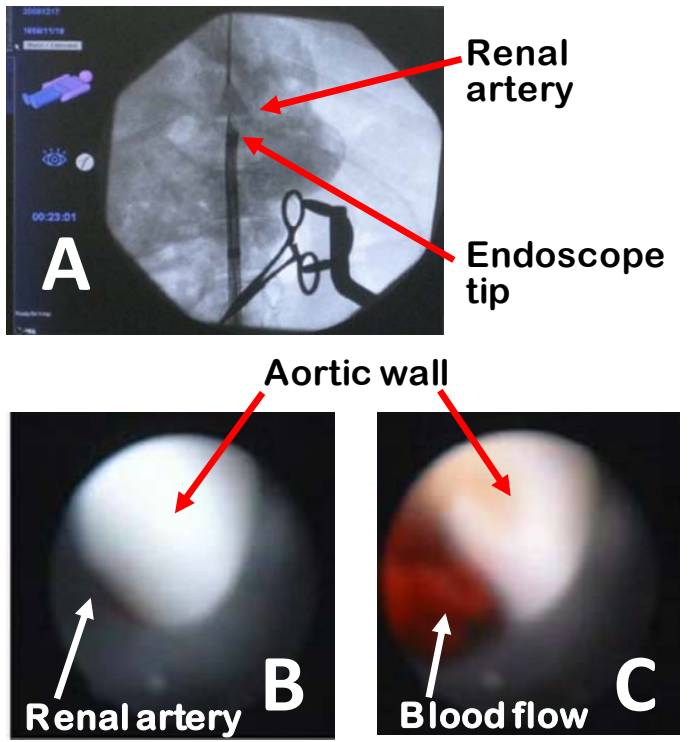

Fig. 8 Examples of the picture obtained by the in vivo experiments 
On the other hand, with $\mathrm{H}-\mathrm{V}$, very high scale values (over 100) were observed with longer period of time even in the very short delay time (50 msec). With this delay time, the pump was still under the systolic phase when the saline jet started to discharge, indicating the effectiveness of the Hemo-visor for improving the quality of the picture.

Fig. 8 shows examples of the pictures obtained by the in vivo experiments. The upper one (A) is an example of the angio graphs. It should be noted that the the endoscope was inserted into the descending aorta and the tip (opening of $\mathrm{H}-\mathrm{V}$ ) was face to the bifurcation of left renal artery. At this position, the endoscope system was operated using ECG-R wave as a trigger signal. The condition of the saline jet at this time was pulse period: $300 \mathrm{msec}$, delay time: $300 \mathrm{msec}$, driving pressure: $0.2 \mathrm{MPa}$, respectively.

The lower two pictures (B and C) in Fig.7 are the examples of the captured picture during the operation. In picture $\mathrm{B}$, a part of the opening of the renal artery was observed (left lower part). From this opening, as shown in the picture C, blood was spurted out intermittently presumably due to the "back pressure" from the peripheral arteries during systolic phase.

\section{CONCLUSION}

A prototype endoscopic system for observing inner wall of large arteries using intermittent saline jet was devised and evaluated by in vitro and in vivo tests. From the results obtained, it was confirmed that using this system the target attached on the inner surface of the tube of the mock circulatory system could be observed without blocking off the fluid stream, and the Hemo-visor was highly effective in improving the quality of picture presumably due to high ability in keeping the saline solution between the tip and the target. Also confirmed was that using this system inner wall of aorta could be observed without stopping blood flow.

From these results, it is suggested that the present method could be a useful assistive technology for the endovascular interventions in aorta. This method is highly invasive and has some difficulties for practical use, although, it requires no large, bulky and extremely expensive instrument as an angiography and has no risk for the exposure to radiation. These two points are quite big practical advantages of our method.

\section{REFERENCE}

[1] S. Tanaka, K. Tokugi, M. Ogawa, K. Motoi, M. Nogawa, H. Ohtake, G. Watanabe and K. Yamakoshi, "Development of a new vascular endoscopic system for observing inner wall of aorta using intermittent saline jet,” WC 2009, IFMBE Proc., 25/VI, pp.217-219, 2009

[2] S. Tanaka, K. Tokugi, M. Ogawa, K. Motoi, M. Nogawa, H. Ohtake, G. Watanabe and K. Yamakoshi, "Development of a Vascular Endoscopic System for Observing Inner Wall of Large Arteries for the Use of Endovascular Intervention," Proceedings of ITAB2010 (CD-ROM), IEEE Catalog Number: CFP10ITA-ART, paper No.123, 2010

[3] For example, "Vecmova NEO, Fiber Tech Inc., Japan” http://www.fibertech.jp/eng/m1_1_2.html

[4] S. Sakai, et al., "Morphologicchanges in infarct-related plaque after coronary stent placement: a serial angioscopy study,” $J$ Am Coll Cardiol., vol.42, pp.1558-1565, 2003

[5] S. Yokoyama, et al., "Extended Follow-Up by Serial Angioscopic Observation for Bare-Metal Stents in Native Coronary Arteries: From Healing Response to Atherosclerotic Transformation of Neointima,” Circ Cardiovasc Interv. vol.2, pp.205-212, 2009

[6] Z. Sun, et al., "CT virtual intravascular endoscopy of abdominal aortic aneurysms treated with suprarenal endovascular stent grafting,” $A b$ dom Imaging, vol.28. pp.580-587, 2003 